\title{
Lefort e a questão da igualdade
}

Lefort and the Issue of Equality

\section{Carlo Gabriel Kszan Pancera Universidade Federal de Minas Gerais | Minas Gerais | Brasil}

\section{RESUMO}

Neste artigo, pretendemos tratar do tema da igualdade em dois momentos do pensamento de Lefort, aqui designados respectivamente de momento republicano e momento democrático. Buscaremos circunscrever os significados que a igualdade adquire em cada um deles. Nossa hipótese é de que não há propriamente discrepância, mas a diferença é derivada do problema que determina a investigação, que é determinada, ora pela questão dos fundamentos do poder, ora pelos rumos da democracia.

\section{PALAVRAS-CHAVE}

Democracia; Igualdade; República; Tocqueville; Maquiavel.

\begin{abstract}
We intend to deal with the theme of equality in two moments of Lefort's thinking: a republican moment and a democratic moment. It is an effort to circumscribe the meanings they acquire in each of them. We will do this under the assumption that there is no discrepancy, but they differ only according to the concern that determines their investigation: sometimes with the foundations of power, sometimes with the paths of democracy.
\end{abstract}

\section{KEY WORDS}

Democracy; Equality; Republic; Tocqueville; Maquiavel. 
Trataremos aqui do tema da igualdade em dois textos de Lefort: Maquiavel: a dimensão econômica do político (1994) e Da igualdade à liberdade (I99I). A temática se faz presente em ambos, mas vinculada a questōes distintas. Naquele, a obra de Maquiavel iria permitir-lhe esclarecer sobre "qual é a função do poder do Estado no processo de formação da sociedade civil" (Lefort, 199I, p. I54), ao passo que neste, a obra de Tocqueville iria ajudá-lo a "decifrar o enigma da democracia" (Ibid., p. 246). Se o enfoque muda em razão da finalidade que o autor tem em vista, o quadro conceitual geral no qual o objeto se insere permanece o mesmo.

No escrito de 1994, sua reflexão encontra-se ainda muito próxima do quadro conceitual formado por categorias derivadas de sua interpretação da obra de Maquiavel, tais como: conflito, lei, poder, povo e liberdade, publicada em $1972^{\mathrm{I}}$ : ele as mobiliza ao longo do referido escrito para levar adiante sua investigação. Já, no de 199I, quando sua atenção volta-se para a questão da democracia moderna, ele parece afastar-se daquele conjunto de categorias. Seria enganoso, porém, pensar que isso acontece de fato; o que explica esse movimento é o próprio objeto: o problema da democracia não é o problema de Maquiavel, mas, em contrapartida, é o de nossa época e, aos olhos de Lefort, quem melhor nos supre com elementos para pensá-la é Tocqueville.

A nosso ver, contudo, o movimento que é feito em direção à questão da igualdade apenas aprofunda um aspecto já presente na obra de Maquiavel. Faz parte do republicanismo do secretário florentino a noção de que a igualdade é condição sine qua non da república e da liberdade, diferentemente do que acontece com um regime principesco, que leva a marca da desigualdade e da servidão (Maquiavel, 2007, I, p. 55; 20IO, \$ I2). Mas, com o advento da revolução democrática na modernidade, que imprime um novo estatuto simbólico ao social, esta oposição perde algo de sua capacidade explicativa. O resultado da referida revolução é a dissolução dos suportes teórico-sociais que davam legitimação à existência da desigualdade. É neste momento que a igualdade torna-se objeto privilegiado de questionamentos. Assim, Lefort, sem abandonar as categorias forjadas no contato com a obra de Maquiavel, as quais lhe deram elementos para pensar os fundamentos do político e do poder, passa, no momento seguinte, a explorar as fortunas da igualdade.

Portanto, os textos escolhidos para nossa análise colocam-se em linha de continuidade. Não se contradizem, nem se diferenciam substancialmente, mas se constituem num desdobramento um do outro, inevitável em razão do deslocamento do contexto do objeto de nossa reflexão. Se, inicialmente, a igualdade é estudada no interior do republicanismo do século XVI, depois, sua referência é a democracia

I Le travail de l'auvre Machiavel, 1972. 
moderna, a qual encontra as condições de emergência no século xvıII. Lefort, ao debruçar-se sobre esse acontecimento, aprofunda um aspecto de sua elaboração teórica, desvelando-nos os caminhos que nos conduzem da igualdade à democracia, mas também sobre as desventuras da igualdade. Feitas estas considerações, é preciso dizer que nosso objetivo neste texto não vai além de buscar delimitar como se insere e com quais conceitos se articula o conceito de igualdade nos referidos escritos.

\section{A igualdade na república}

O primeiro texto não parece se destacar muito das teses expostas da obra Maquiavel: o trabalho da obra (1972), publicado dois anos antes e resultado de longos anos de elaboração. Nesse momento, reconhecemos a atribuição de um papel central para os conflitos no desenvolvimento de sua análise. Este é um traço marcante de sua interpretação de Maquiavel. Na obra do secretário florentino, tal noção redunda na formulação de um modelo de república. Não é o caso de Lefort, a despeito do caráter estruturante para seu pensamento da interpretação da obra do secretário florentino (Bignotto, 2013, p. 34 e seguintes). Mas ambos se aproximam pelas categorias que mobilizam. Seja como for, é ainda no interior desse contexto teórico-conceitual que a discussão sobre a igualdade surge.

A interpretação de Lefort sobre as relações entre o político e o econômico na obra de Maquiavel permite-lhe estabelecer a função do poder do Estado na formação da sociedade civil (Lefort, 1994, p. I54). Para fazê-lo, ele toma distância relativamente a duas posiçôes, uma das quais remete ao seu próprio contexto político-ideológico, enquanto a outra coloca-nos mais próximo das interpretações de Maquiavel. Assim, vamos encontrar, de um lado, as teorias de cunho marxista que, para compreender a função do Estado, põem acento no aspecto econômico; de modo geral, e até mesmo caricatural, pode-se dizer que elas supõem a preponderância do elemento econômico sobre o político e, assim, o Estado passa a ser um reflexo puro e simples da luta e posse dos meios de produção — uma espécie de epifenômeno do econômico, uma instituição que serve às classes dominantes (Ibid., p. I53). De outro lado, encontramos as leituras, normalmente ancoradas em Maquiavel, que afirmam ter o autor descoberto e afirmado a autonomia do político; aqui se dá o inverso, ocorrendo a preponderância do político sobre o econômico. Verso e reverso, esta serve de leitura para aquela.

Lefort recusa as duas posições. A perspectiva marxista é insatisfatória porque perde de vista o papel central do conflito político e, com isso, não percebe claramente a dinâmica da constituição do Estado e da transformação histórica (Ibid.). Maquiavel oferece um saída para isso quando faz dele o operador principal de sua análise. O problema que surge, então, é colocado por aqueles que veem no pensamento do secretário florentino a afirmação cabal da autonomia do 
político. Isso geraria uma grande dificuldade para Lefort, pois é inegável o peso do elemento econômico para a compreensão do fenômeno político. Se assim the parecesse, talvez sua obra também fosse alvo de recusa.

Não obstante as acusações, Lefort, no primeiro momento do texto, ocupa-se em demonstrar que tal leitura não se sustenta. Parece-lhe equivocado o entendimento de que Maquiavel desconhecia ou ignorava as coisas relativas à economia e, consequentemente, voltava sua atenção unicamente para o aspecto político. Não obstante a afirmação em contrário que faz na carta que envia a Vettori, tanto a inserção histórica do autor numa república com um sistema econômico altamente desenvolvido para a época, quanto evidências textuais interditam esta leitura. Dois textos anteriores às grandes obras teóricas são especialmente adequados para tanto: O Retrato das coisas da Alemanha e o Retrato das coisas da França são, em parte, dedicados à análise da questão econômica de cada um desses estados. A despeito disso, é fato o obscurecimento desse elemento, o qual ocorre, por exemplo, em certas passagens do Príncipe referentes à França e a Alemanha. Como explicá-lo?

A hipótese levantada por Lefort é a de que está operando na obra do secretário florentino uma concepção mais abrangente de política, semelhante à do período clássico. Para compreendermos isso, contudo, é preciso realizar um deslocamento do conceito do político para trás no tempo. Este reposicionamento implica em tomar-se tal conceito numa acepção mais abrangente, de modo que a divisão política grandes/povo, fundante para o pensamento maquiaveliano, é o que decide no final das contas a forma das relações sociais, ou seja, aquela é anterior e determinante desta (Ibid., p. I44). Assim, se a questão do poder está no centro de sua reflexão, é porque ela antecede as demais relações, que são por ela produzidas: "a sorte da divisão social se decide em função do modo de divisão do poder e da sociedade civil e que, assim, se determinam as condiçôes gerais dos diversos tipos de sociedade" (Ibid.). Ou seja, o político recobre o econômico, mas não o exclui. Nessa divisão política que, para Lefort, é uma divisão de desejos, que somente ocorre quando o campo político está estabelecido, o econômico está dado com a determinação política, a exemplo do que ocorre com o emblema dos grandes (Ibid., pp. I45-I46).

O estado surge dessa divisão e é marcado por ela. Neste contexto é que podemos e devemos situar o problema da igualdade. Conforme tal divisão ocorre, são produzidos tipos sociais distintos, aos quais correspondem monarquias e repúblicas. Estas são oposições fundamentais para Maquiavel/Lefort. A igualdade, neste contexto teórico, não designa um fato puro, seja ele jurídico, político ou econômico. Tampouco pode ser percebido no campo da realidade empírica - aqui, percebemos apenas os sinais da desigualdade. Para Lefort, a igualdade indica uma relação simbólica num certo tipo de sociedade política (Ibid., p. I48). 
Dito de outro modo, a igualdade designa um campo do social que se torna igual a si mesmo, isto é, homogêneo. Neste caso, exclusivamente, a divisão se apresenta como puramente social, diferentemente da desigualdade, em que o elemento político se faz presente, tornado manifesto nas relaçōes hierárquicas (Ibid.).

\section{A igualdade na democracia}

Ponto de chegada do escrito acima, a igualdade torna-se o foco principal do texto Da Igualdade à liberdade. Nele, Lefort interpreta passagens importantes de A democracia na América, sempre atento às indeterminaçôes do pensamento de Tocqueville (Lefort, I99I, p. 227). Entre as idas e vindas, paradoxos e eventuais contradiçôes da argumentação da obra examinada de que o intérprete maquiaveliano se ocupa, conseguimos vislumbrar uma série de facetas da igualdade. Essas múltiplas facetas contribuem para melhor formular e, quiçá, compreender o enigma da democracia (Ibid.) para além dos pensadores seus contemporâneos, fossem eles burgueses democratas ou socialistas (Ibid., p. 246). Aqui, contudo, não iremos acompanhar todos os meandros da argumentação lefortiana, mas apenas o seu desdobramento final, naquilo que se refere às ameaças contidas na igualdade. Diferentemente do realizado acima, contudo, recorremos com mais frequência ao autor interpretado por Lefort, inclusive para tornar mais explícito o ponto sobre o qual incide mais fortemente a sua atenção.

Lefort reconhece na sociedade moderna ecos da época democrática ${ }^{2}$ descrita por Tocqueville. Encontra aí um terreno fértil para suas reflexões. O que, porém, caracteriza-a como tal? Segundo Tocqueville, a caracterização de uma época depende da delimitação do fato singular e dominante que lhe é próprio. Este fato produz um pensamento mãe ou uma paixão principal à qual todas as demais estão ligadas (Tocqueville, I977, p. 384). Por isso, se, na tipificação de seu período, descarta a liberdade como traço marcante, não é porque ela não se faça presente, mas por não lhe ser exclusiva, podendo ser encontrada em outros períodos históricos. $\mathrm{O}$ atributo que melhor parece caracterizar sua época é a igualdade. É ela, ou melhor, é a paixão por ela que mobiliza todos os homens e suas ações (Ibid.). É para este traço da sociedade moderna que se volta Lefort.

Vivemos, pois, num século democrático, marcado pela igualdade. Em boa medida, pode-se dizer que a liberdade lhe é correlata. É quase uma consequência natural. Conforme diz Tocqueville, os homens não poderiam tornar-se iguais sem serem inteiramente livres (Ibid.). Este vínculo entre igualdade e liberdade coloca-nos problemas. Mas é também na relação entre uma e outra que reside a questão que

2 O texto de Tocqueville trata as expressões épocas de igualdade e épocas democráticas como expressões intercambiáveis. Na nossa exposição, preferiremos esta última. 
comanda a obra Democracia na América (Lefort, 1991, p. 227). Mas, se quisermos avançar nossa investigação em direção às ameaças que rondam a democracia ou, ainda, sobre as ameaças contidas na igualdade, teremos que fazer um esforço rumo a uma melhor distinção dos dois termos — igualdade e liberdade — sobre os quais se estrutura o problema.

Certamente, é uma distinção difícil de ser feita, pois, como dissemos acima, a igualdade não se faz sem alguma dose de liberdade. Ou seja, a afirmação da igualdade sempre vem acompanhada da afirmação da independência em relação a outros homens, independência esta que, mesmo dizendo respeito apenas ao indivíduo, encarna um grau mínimo de liberdade. Num grau máximo, que conforma o ideal a que todos os povos democráticos tenderiam (Tocqueville, I977, p. 383), Tocqueville também coloca esses termos em relação; assim, ele supõe ser possível imaginar um caso em que ambas se sobrepóem de tal modo que "os homens serão perfeitamente livres, porque todos serão inteiramente iguais, e todos serão perfeitamente iguais porque serão inteiramente livres" (Ibid.). Em qualquer destes limites, portanto, parece ser difícil distinguir os termos.

O expediente para tanto está justamente em tomar em consideração a paixão prevalente: se é a paixão pela igualdade ou é a paixão pela liberdade. Sem nos determos em todas as razões apontadas por Tocqueville, basta-nos constatar que a paixão pela igualdade é mais forte e persistente, a ponto de obscurecer a paixão pela liberdade. Os povos democráticos "têm pela igualdade uma paixão ardente, insaciável, eterna, invencível"; preferem-na à liberdade. O caso extremo demonstra-o: "ainda a desejam na escravidão. Suportarão [...] a servidão, a barbárie, mas não suportarão a aristocracia” (Ibid., pp. 385-386). Neste limite extremo, portanto, pode-se entrever um momento em que uma suplanta a outra, o que, a nosso ver, nos autoriza a cuidar da igualdade dissociada da liberdade. Por essa via, podemos melhor aquilatar os desvãos da igualdade naquilo que ela tem ou pode ter de nocivo. E é justamente o que faz Lefort seguindo Tocqueville: explora o resultado desta dissociação, isto é, explora a possibilidade da existência da igualdade sem liberdade (Lefort, I99I, p. 228 e p. 230).

\subsection{Individualismo e anarquia}

As ameaças contidas na igualdade são o anarquismo e o despotismo. Ambas são consequência do individualismo, fruto do desenvolvimento da igualdade sob o aspecto da independência pessoal, conforme veremos abaixo. Tal estado é ponto de passagem tanto para um quanto para outro: vai-se do individualismo à anarquia, mas também do individualismo ao despotismo. Por isso, é preciso caracterizá-lo minimamente para podermos prosseguir. Nesta caracterização, creio ser útil fazer uso da oposição entre dois operadores teóricos, a saber: o de povo democrático e o de povo aristocrático (Tocqueville, I977, pp. 386-387; p. 392; p. 427; p. 513; 
p. 516; p. 519), operadores estes que Tocqueville frequentemente lança mão e que Lefort designa, respectivamente, como fenômeno da dissociação e fenômeno da associação (Lefort, I99I, p. 234).

Este último, fenômeno típico de um século aristocrático, é uma espécie de força centrípeta, que tende a agregar os homens em torno de centros de poder ou em classes (Tocqueville, 1977, p. 392) As instituições que encarnam tais centros e classes mantêm os homens unidos por meio de laços bastante fortes (Ibid., p. 386). Em certa medida, a liberdade encontra-se marcada por essa tendência, já que remete à ideia de associação entre os homens, embora não se confunda nem caracterize o referido século. As sociedades marcadas por vínculos dessa natureza são avessas ao novo e, por isso, tendem a ser estáveis.

O fenômeno da dissociação, em contrapartida, opera como uma força centrífuga, que leva os homens à dispersão. A lógica que subjaz este raciocínio é a de que os sujeitos, uma vez em estado de igualdade, buscam aprofundar tal estado por meio da busca de mais independência pessoal e, caminhando nesta trilha, tendem a isolar-se. Perdem de vista a sociedade e seus vínculos com ela e concentram-se em si mesmos e no aprofundamento de sua condição.

Esta tendência é mais ou menos marcante, nos diz Tocqueville, conforme o processo pelo qual se chegou à condição de igualdade: se como um dado constitutivo de um novo corpo político, a exemplo da América, ou como resultado de uma Revolução Democrática, a exemplo da Europa continental e, mais especificamente, da França. Neste caso, inicialmente, tal estado de igualdade foi resultado de um processo de nivelamento por que passaram as sociedades sob governos de reis e monarcas absolutistas (Ibid., p. 385; Lefort, I99I, p. 232). Mas, quando, finalmente, irrompeu no seio da sociedade, pondo abaixo estruturas hierárquicas, a violência com que isso se deu empurrou os homens para o extremo oposto, o da completa recusa de qualquer estrutura de governo. Explico.

Com a dissolução de tais sistemas políticos, a igualdade se vê livre dos óbices que impediam seu desenvolvimento. A rejeição a tais sistemas e, talvez, o medo que ainda inspira, leva os homens a posicionarem-se no extremo oposto, que é justamente o isolamento, fruto da radicalização da crença na independência pessoal. É a esta tendência que Tocqueville designa de individualismo (Tocqueville, 1977, p. 386). Neste sentido, os países que passaram por uma revolução democrática são um terreno mais propício para o individualismo do que os países em que esta condição se estabeleceu de modo quase natural (Ibid., p. 385). Mas se isto explica a causa, não esgota o argumento.

É claro, nos alerta Tocqueville, que outros elementos tornam a delimitação das causas mais complexas. Diferentemente dos séculos aristocráticos, nos séculos democráticos os vínculos entre os homens são mais amplos — não são mais com a 
classe, mas com os homens em sua totalidade, vale dizer, com a humanidade mas, em contrapartida, são mais fracos. Isso os torna mais suscetíveis a serem rompidos (Ibid., p. 386). Some-se a isto a constatação de que os homens médios, dotados de alguma luz e de meios materiais o suficiente, creem bastar-se a si mesmos e não dependerem de mais ninguém; vale dizer, "habituam-se a se considerar sempre isoladamente, e de bom grado imaginam que seu inteiro destino está entre as suas mãos" (Ibid., p. 387).

Desse modo, se contabilizarmos a radicalização da crença na independência individual, a frouxidão dos laços que unem os homens e sua oposição ao sistema anterior, elementos que caracterizam o individualismo, não fica difícil vermos que no horizonte afigura-se a fragmentação do corpo social, cuja representação política é a anarquia. Trata-se de uma espécie de vazio social e de poder.

A esta conclusão, no entanto, deve-se apor uma objeção, segundo Lefort. Para ele, a dissolução da sociedade e do estado não é o maior problema de Tocqueville, pois ele é episódico, a ponto desse vazio de poder constituir-se mesmo numa fiç̧ão (Lefort, I99I, p. 239). De fato, o real objeto de preocupação do autor de A Democracia na América é o tipo de despotismo capaz de emergir de um século democrático. Trata-se aqui de um fenômeno novo, que não encontrava no vocabulário corrente uma expressão adequada (Tocqueville, 1977, p. 512). É a descrição deste novo fenômeno que atraiu os olhares de muitos interessados e que agora atrai também o olhar de Lefort. Creio não ser equivocado supor que ele reconhece em tal fenômeno elementos que, não só descrevem algo da sociedade moderna, mas a existência nela de alguns elementos totalitários. Vejamos como Tocqueville chega a ele.

\subsection{Do individualismo ao despotismo: o poder tutelar}

A igualdade instila no homem o desejo de independência total, a qual deságua no individualismo (Tocqueville, I977, p. 5II) e é marcado politicamente pelo descontentamento com toda e qualquer autoridade. Tal individualismo, por sua vez, pode gerar efeitos políticos nefastos. Tanto pode redundar na anarquia quanto na servidão (Ibid., p. 5I2). O primeiro destes casos, tratado acima, é um mal menor, posto que passageiro (Ibid.). É o outro que deve ser objeto de real atenção e preocupação. Para compreendermos o caminho que pode levar à concretização de tal ameaça, é preciso mais uma vez atentar para a dinâmica da igualdade.

Os povos democráticos, diz Tocqueville, têm sempre no seu horizonte uma ideia simples do poder: pensam-no ordinariamente como único e centralizado. Tal ideia se conjuga com outra, a de uma legislação uniforme. Ambas se constituem no contraponto ao que ocorre nas sociedades aristocráticas, onde existem poderes intermediários, lugar institucional da nobreza, e privilégios, distinçôes hierárquicas inscritas na ordem social e na ordem jurídica (Ibid., pp. 5I2-513). 
Subjacente a tais ideias típicas dos referidos povos democráticos, encontramos um processo de nivelamento e de igualação dos homens que, à medida que se desenvolve, resulta no crescimento da sociedade, a qual passa aos poucos a sobreporse aos indivíduos. A lógica que explica a ascensão daquela e a dissolução destes é a da progressiva identificação dos indivíduos, que se tornam cada vez mais semelhantes. O que se vê a partir de então não é mais a imagem dos indivíduos, mas a deles dissolvidos numa multidão, portadora das características comuns, a que se nomeia de povo (Ibid., p. 513). Este é um ponto crucial para Lefort. No comentário que tece a este ponto da argumentação de Tocqueville, reconhecemos algumas categorias que depois ele vai mobilizar para pensar o totalitarismo (Lefort, I99I, p. 24I).

Juntamente com as ideias que os povos democráticos têm do poder e da legislação, também contribui para constituição de um poder único e central os hábitos e os sentimentos desses povos. A recusa de reconhecer alguém como superior ou inferior, a falta de tempo para os afazeres públicos, o amor à tranquilidade, ódio aos privilégios, além, é claro, da paixão pela independência que, paradoxalmente, torna os homens frágeis, são fatores que os predispõem para tanto. Desse modo, somando-se tudo, a centralização constitui-se quase que numa tendência natural (Tocqueville, 1977, p. 517), mais ou menos forte conforme o modo como se funda a igualdade (Ibid., p. 5I8), de acordo com o que mostramos acima.

Tocqueville parte de tais premissas para antever o surgimento de um novo tipo de despotismo, um fenômeno novo sem representação ou inexistente anteriormente (Ibid., p. 53I). Novamente, Lefort fica atento a esse aspecto por causa da dinâmica do pensamento do autor de $A$ Democracia na América. Tal dinâmica permite fazer uma descrição do que viria a ser a exacerbação desta tendência dos povos democráticos que viria a desaguar politicamente na constituição de um poder central e único.

Trata-se agora de um "poder imenso e tutelar" (Ibid.). Por detrás do movimento que conduz os povos democráticos nessa direção encontramos o confronto de duas paixôes inimigas: de um lado, a necessidade dos homens de serem conduzidos, de modo que fiquem liberados para cuidar de seus interesses privados, e, de outro, o desejo de permanecerem livres, continuando a determinar o seu próprio destino, sem se submeterem a um senhor (Ibid., p. 532). O arranjo político que é capaz de satisfazer a ambos é uma espécie de poder tutelar, cujo representante seja eleito. Assim, aparentemente, seria possível transferir ao poder central uma série de atribuiçôes referentes ao interesse comum, ao mesmo tempo em que seria possível impor algum controle sobre ele. Dito de outro modo, teríamos um estado centralizado, cuja soberania, porém, permaneceria na mão do povo.

Ocorre que a servidão impor-se-ia sub-repticiamente. A escolha do 
representante do poder central não retira os homens verdadeiramente da dependência, pois, isso feito, logo voltam, diz Tocqueville, ao domínio do novo senhor eleito (Ibid.). A liberdade é obliterada aos poucos: "esse uso tão importante, mas tão curto e raro, do seu livre arbítrio, não impedirá que percam pouco a pouco a faculdade de pensar, de sentir e de agir por si mesmos..." (Ibid., p. 533). A consequência é a de tornarem-se incapazes de exercerem este papel; daí ser difícil imaginar um povo servil elegendo um governo liberal (Ibid.).

A redução dos homens à condição de animais ou de crianças, incapazes de usarem o livre-arbítrio e de exprimirem sua vontade, aprofunda a centralização do poder, que se torna absoluto. Some-se a isto a necessidade de uma legislação uniforme, que, para ser efetiva precisa ser minuciosa e espraiada pela sociedade e, ainda mais, a ruptura dos laços e vínculos que unem os homens que, isolados, se desumanizam (Ibid., p. 530). Considerando tudo isso, teremos a descrição deste novo fenômeno, desse "poder imenso e tutelar", caracterizado por Tocqueville como "absoluto, minucioso, regular, previdente e brando", que, no final das contas, entrega o homem a um estado de servidão (Lefort, I99I, p. 245).

Lefort, por sua vez, reconhece nesse processo um caminho que leva ao totalitarismo, embora não diga isso explicitamente no texto A lógica totalitária (20II). A referida identificação dos homens entre si na figura do povo, tal como descrevera Tocqueville, leva, segundo ele, à imagem do povo-Uno (Lefort, 20II, p. 98). Do mesmo modo, a explicação tocquevilliana sobre a dissolução dos indivíduos reduzidos à mera multidão e a sua substituição pela sociedade conduz Lefort a uma melhor compreensão desse lugar que, para ele, encarna o real todo-poderoso (Ibid., p. IOO). Ainda, ele associa a estas duas categorias outra: a de um poder despótico, que, ao mesmo tempo em que encarna o povo, representa a sociedade, absorvendo-a, tornando-se indistinto dela (Ibid.). Esta instância de poder paira assim sobre uma multiplicidade de indivíduos, vale dizer, sobre o rebaixamento universal, e remete no final das contas à noção de poder social, que elimina toda divisão do corpo político (Ibid., pp. 96-97).

Enfim, quando chegamos a este ponto, estamos próximos da caracterização de uma nova forma de despotismo, um poder total e esmagador, que somente emergirá no século vinte, mas cujas causas Tocqueville já nos fazia entrever quando explorava os desvãos da democracia no século anterior.

\section{Epílogo}

Lefort acompanha Tocqueville até o fim na sua argumentação. E o faz, creio, para deixar manifesto que a igualdade traz em si também o seu remédio, mesmo no interior deste despotismo acima descrito. Ela permanecerá inscrita no corpo social e trará com ela sempre a possibilidade da liberdade: "Esses instintos se repetirão 
todos os dias porque eles pertencem ao estado social que jamais mudará. Durante muito tempo, impedirão que algum despotismo possa se estabelecer e fornecerão novas armas a cada nova geração que queira lutar em favor da liberdade dos homens" (Lefort, I99I, p. 245).

\section{Referências}

Adverse, Helton (2010) (Org.). Maquiavel: Diálogo sobre nossa língua e Discurso sobre as formas de governo de Florença, Belo Horizonte: UFMG.

Bignotto, Newton (20I3). "Lefort e Machiavelli", In Martín Plot (Ed.), Claude Lefort. Thinker of the Political, Basingstok: Palgrave Macmillan.

Lefort, Claude (1972). Le travail de l'œuvre Machiavel, Paris: Gallimar.

Lefort, Claude (199I). "Da liberdade à igualdade" (1978), In Pensando o Político. Ensaios sobre democracia, revolução e liberdade, trad. Eliana M. Souza, São Paulo: Paz e Terra.

Lefort, Claude (1994). "Maquiavel: a dimensão econômica do político" (1974), In As Formas da História. Ensaios de antropologia política, trad. Luiz Roberto Salinas Fortes e Marilena de Souza Chauí, São Paulo: Brasiliense.

Lefort, Claude (20II). "A lógica totalitária" (1980), In A invenção democrática. Os limites da dominação totalitária, trad. Isabel Loureiro e Maria Leonor Loureiro, Belo Horizonte: Nupsi/Autêntica.

Machiavelli (1997). Opere, a cura de Corrado Vivanti, Torino: Einaude-Gallimard.

Maquiavel, Nicolau (2007). Discursos sobre a primeira década de Tito Livio, trad. MF, São Paulo: Martins Fontes.

Tocqueville, Alexis de (1977). A Democracia na América, trad. Neil Ribeiro da Silva, Belo Horizonte: Itatiaia/São Paulo: EDUSP. 